\title{
Composition Analysis of a Thin Gate Oxide Layer using Model-Based EELS Quantification
}

\author{
Qiang Jin \\ Micron Technology, Inc., 8000 S. Federal Way, P.O. Box 6, Boise, Idaho 83707
}

The reductions of device dimensions in MOSFET technologies demand the introduction of thin gate oxides with thicknesses of a few nanometers. The electrical properties of such layers vary strongly with the structure and composition near the $\mathrm{SiO}_{\mathrm{x}} / \mathrm{Si}$ interface. It is therefore of critical importance to be able to quantify the gate oxide composition with a high spatial resolution. Electron energy-loss spectroscopy (EELS) is often used for this purpose. However, the interaction of incident electrons with both $\mathrm{SiO}_{\mathrm{x}}$ and $\mathrm{Si}$ makes conventional EELS quantification [1] impossible near the $\mathrm{SiO}_{\mathrm{x}} / \mathrm{Si}$ interface. To separate this overlapping effect, model-based quantification of EEL spectra has to be employed $[2,3]$.The results obtained on a thin gate oxide layer making use of this technique are presented in this paper.

The TEM sample was prepared by focused ion beam (FIB) milling, with the final thickness of the specimen around $100 \mathrm{~nm}$. A cross-sectional high resolution TEM image of the gate oxide is shown in Fig. 1a. EELS spectra with an energy resolution of $1.5 \mathrm{eV}$ were collected simultaneously with a high-resolution Z-contrast STEM (scanning transmission electron microscopy) image (Fig.1b). The estimated probe size was $0.2 \mathrm{~nm}$ and the convergence and collection half-angle were respectively 18 $\mathrm{mrad}$ and $47 \mathrm{mrad}$. The conventional composition analysis uses the core-loss edges of $\mathrm{O}$ and $\mathrm{Si}$ with the concentration ratio proportional to the edge integral ratio. This method only works for locations certain distances away from the $\mathrm{SiO}_{\mathrm{x}} / \mathrm{Si}$ interface where no edge overlapping occurs. As shown in Fig.2c, near the $\mathrm{SiO}_{\mathrm{x}} / \mathrm{Si}$ interface, both $\mathrm{Si}$ and $\mathrm{SiO}_{\mathrm{x}}$ contribute to the $\mathrm{Si}$ signal which is essentially an overlap between two distinct $\mathrm{Si}-\mathrm{L}_{2,3}$ edges (Figs. $2 \mathrm{a}$ and $2 \mathrm{~b}$ ) with an energy shift of about $5 \mathrm{eV}$. Accurate composition analysis requires determination of the Si signal contributed by the gate oxide only. This can be achieved using the so-called model-based quantification method [2,3]. Si and O were analyzed independently using two different models. In Si analysis, the model includes two Si$\mathrm{L}_{23}$ edges from $\mathrm{Si}$ and $\mathrm{SiO}_{\mathrm{x}}$ respectively and their corresponding fine structures, which are determined experimentally from locations well away from the $\mathrm{SiO}_{\mathrm{x}} / \mathrm{Si}$ interface. Multiple scattering effect is taken into consideration through convolution of the single-scattering core-loss spectrum with a low-loss spectrum. The cross-section ratio of $\mathrm{O}-\mathrm{K} / \mathrm{Si}^{-} \mathrm{L}_{2,3}$ was calibrated using a standard $\mathrm{SiO}_{2}$ sample. In Fig.3, the composition profile obtained using the model-based method is compared with that obtained from the conventional method where the total Si signal is used. Significant differences were found between the two methods near the $\mathrm{SiO}_{\mathrm{x}} / \mathrm{Si}$ interface. It should be noted that the accuracy of the model-based quantification is governed by the statistical quality of the spectrum and the accuracy of the cross-section ratio. In this work, the accuracy is estimated to be about $5 \%$. It is suggested that the model-based method should be used for EELS quantification in case that the ionization edges of interest are overlapped and the conventional method fails to provide accurate results.

\section{References}

[1] R.F. Egerton, Electron Energy Loss Spectroscopy in the Electron Microscope, second ed., Plenum Press, New York, 1996.

[2] J. Verbeeck, S. Van Avert, Ultramicroscopy 101(2004) 207. 
[3] J. Verbeeck, S. Van Avert, G. Bertoni, Ultramicroscopy 106 (2006) 976.
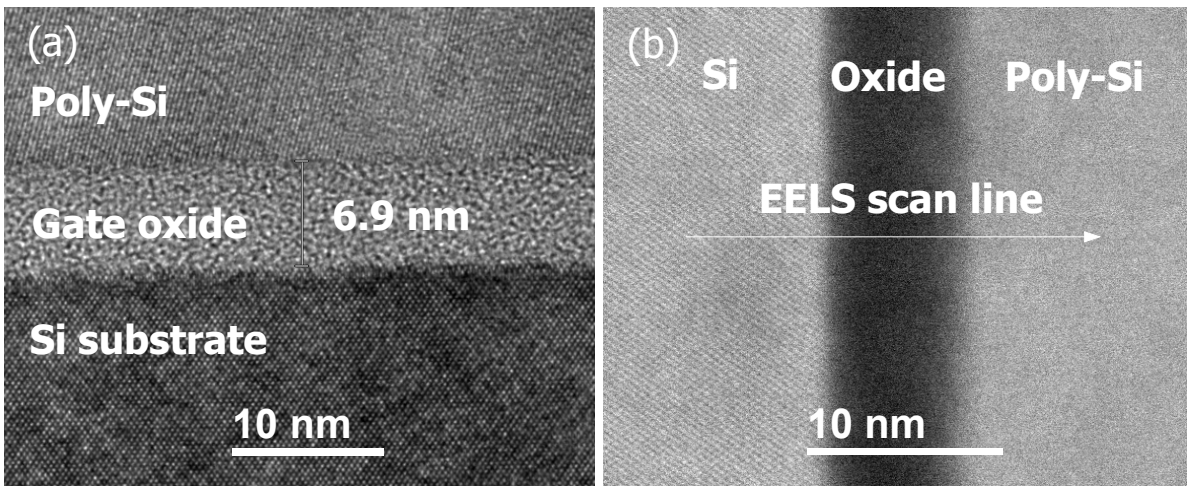

FIG.1. (a) Cross-section high-resolution TEM image of the gate oxide, (b) High-resolution STEM image of the gate oxide and the position of the EELS line scan.

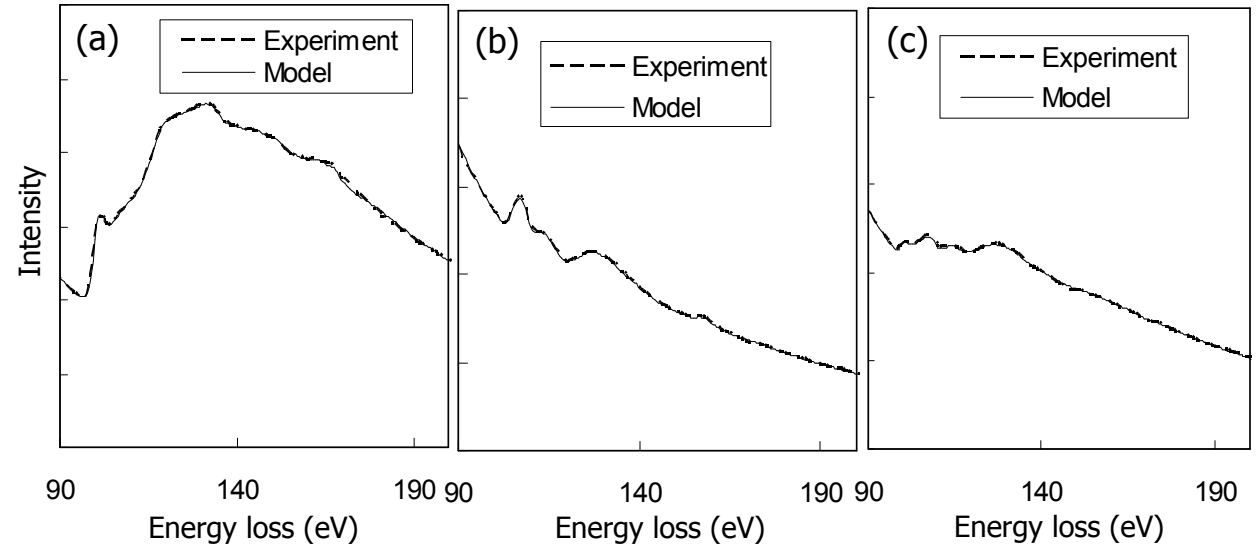

FIG. 2. Typical EELS spectrum of $\mathrm{Si}-\mathrm{L}_{23}$ edge (dashed line) obtained in $\mathrm{Si}(\mathrm{a}), \mathrm{SiO}_{\mathrm{x}}(\mathrm{b})$ and near the $\mathrm{SiO}_{\mathrm{x}} / \mathrm{Si}$ interface (c). The simulated spectrum (solid line) is also shown for comparison.

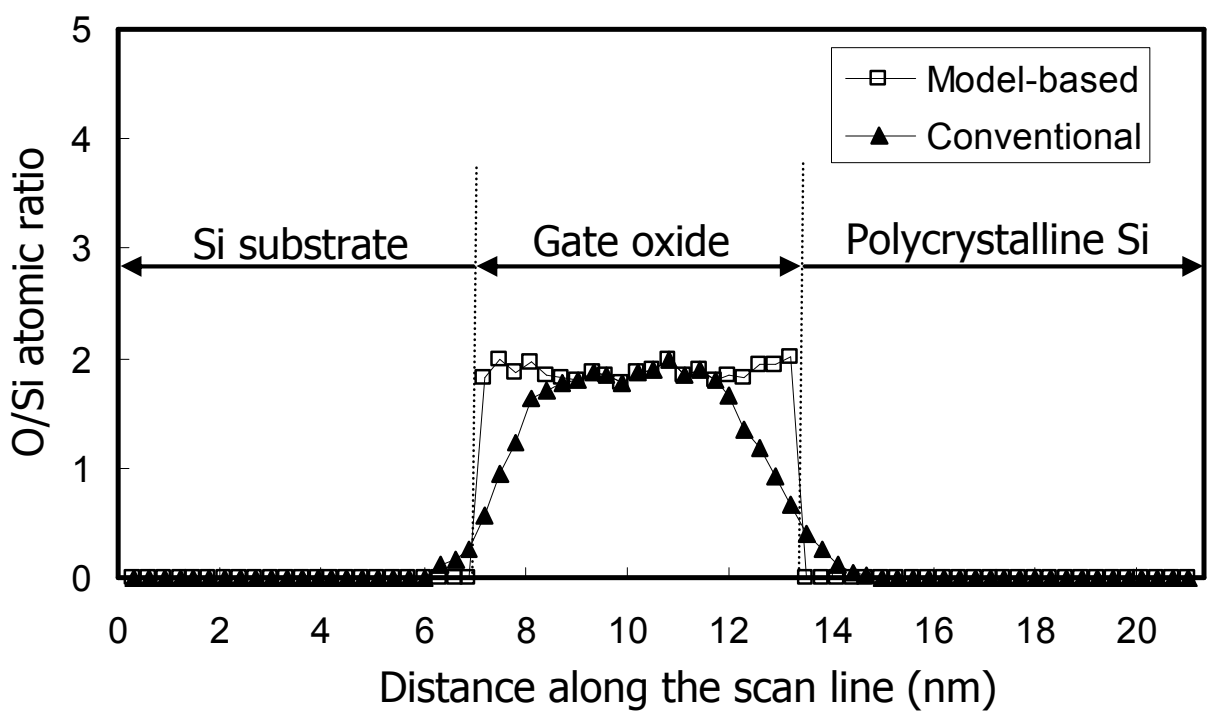

FIG.3. Comparison between the composition profiles obtained with the model-based method and the conventional method. In the latter case, the total $\mathrm{Si}$ signal from both $\mathrm{Si}$ and $\mathrm{SiO}_{\mathrm{x}}$ is involved in $\mathrm{O} / \mathrm{Si}$ ratio determination near the $\mathrm{SiO}_{\mathrm{x}} / \mathrm{Si}$ interface. 